\title{
Revisiting the Criteria for Exchange Transfusion for Severe Neonatal Hyperbilirubinemia in Resource-Limited Settings
}

\author{
Bolajoko O. Olusanya ${ }^{a}$ Zainab O. Imam ${ }^{b}$ Abieyuwa A. Emokpae ${ }^{b}$ \\ Iman F. Iskander ${ }^{\mathrm{C}}$ \\ ${ }^{a}$ Centre for Healthy Start Initiative, and ${ }^{b}$ Massey Street Children's Hospital, Lagos, Nigeria; ${ }^{\mathrm{C}}$ Department of \\ Paediatrics, Cairo University, Cairo, Egypt
}

\section{Key Words}

Bilirubin encephalopathy · Kernicterus · Neurotoxicity ·

Hemolysis · Developing countries

\begin{abstract}
Background: Exchange transfusion (ET) for severe neonatal hyperbilirubinemia (SNH) is frequently undertaken in lowand middle-income countries (LMIC), in sharp contrast to the prevailing practice in high-income countries. However, the criteria for initiating this procedure in settings with limited resources for treating infants with $\mathrm{SNH}$ have not been systematically explored. Objective: To identify key considerations for initiating ET in resource-poor countries to curtail its unnecessary use for the prevention of kernicterus. Methods: A review of the existing guidelines and literature on the management of neonatal hyperbilirubinemia worldwide was conducted to identify criteria and underlying factors for initiating ET. Results: There is a dearth of evidence from randomized clinical trials to support clear criteria for indicated ET worldwide. Because risk assessment for kernicterus based solely on the levels of total serum bilirubin (TSB) has often proved inadequate, a combination of plasma/serum bilirubin estimation and clinical evaluation for acute bilirubin encephalopathy (ABE) has been recommended for predicting the risk of kernicterus. However, there is a lack of consistency regarding the TSB levels for which ET should be initiated in
\end{abstract}

relation to the clinical signs/symptoms of $A B E$ and hemolytic disorders. Conclusions: A decision-making framework that combines TSB thresholds and evidence of neurotoxicity is needed for evaluating the risk of kernicterus and prioritising infants for ET in LMICs to curtail unnecessary interventions.

(c) 2015 S. Karger AG, Basel

\section{Introduction}

Since its introduction in the late 1940s [1], exchange transfusion (ET) has been universally established as an efficacious and reliable treatment for severe neonatal hyperbilirubinemia $(\mathrm{SNH})$ and the prevention of bilirubininduced neonatal mortality and long-term morbidity [24]. This clinical procedure, which is not entirely risk free, lowers the total plasma/serum bilirubin (TSB) concentration by removing circulating bilirubin, antibody-coated red blood cells in hemolytic disease (e.g. in rhesus and ABO sensitization), or vulnerable red blood cells due to glucose-6-phospho-dehydrogenase (G-6-PD) deficiency and other red cell enzyme deficiencies [5]. Adverse events associated with ET, even in settings with advanced clinical care, include sepsis, electrolyte imbalance, air embolism, portal vein thrombosis, cardiac overload, thrombophlebitis, thrombocytopenia, and necrotizing enterocolitis, as well as the transmission of blood-borne diseases

\section{KARGER}

E-Mail karger@karger.com

www.karger.com/neo
C 2015 S. Karger AG, Basel

$1661-7800 / 15 / 1092-0097 \$ 39.50 / 0$ 
[4-6]. ET is therefore, generally regarded as the last line of defense after phototherapy has failed to lower TSB to safe levels in babies with SNH or has been ineffective in preventing rapidly rising bilirubin levels in infants with hemolytic SNH $[2,7]$.

The requirement for ET in developed countries has declined largely due to improved surveillance of infants with clinically significant jaundice, routine use of rhesus immunoglobulin prophylaxis to prevent primary isoimmunization of Rh-negative women, and optimization of blue-light phototherapy $[8,9]$. In contrast, excessive rates of ET, with its associated risks, persist in low- and middleincome countries (LMIC) $[4,10,11]$. A hospital-based study from the Middle East found that 99 (61.1\%) of 162 infants admitted for $\mathrm{SNH}$ over a 4 -month period received ET [11]. Another study from Latin America reported that $78(21.5 \%)$ of 362 infants who received phototherapy over a 5-year period still required ET [4].

Striking a balance between undertreatment and overtreatment in LMIC is complicated by several factors including the prevalence of hemolytic triggers unique to many LMIC, the late presentation of severe cases, and the lack of adequate clinical and laboratory facilities [11-13]. This paper reviews the existing criteria for initiating ET in late-preterm and term infants with $\mathrm{SNH}$ and how these can be optimized to provide timely (while avoiding unnecessary) ET in resource-poor countries. It excludes discussions regarding the technique, resources, and provider expertise for the procedure as these are well described in the literature $[5,14]$.

\section{Methods}

The key terms used in this review are consistent with American Academy of Pediatrics (AAP) guidelines for the management of neonatal hyperbilirubinemia [7]. For example, SNH refers to neonatal jaundice with serum bilirubin at/near ET levels based on postnatal age and etiology, and/or any elevated bilirubin levels associated with signs of acute bilirubin encephalopathy (ABE). The term $\mathrm{ABE}$ refers to the acute manifestations of bilirubin toxicity seen in the first weeks after birth. Signs and symptoms of ABE are typically classified as mild (poor feeding, lethargy, and tone abnormalities), moderate/intermediate (high-pitched cry, irritability, and increasing hypertonia), or severe/advanced (deep stupor, fever, apnea, inability to feed, retrocollis, opisthotonus, and obtundation). The term kernicterus refers to the chronic and permanent clinical sequelae of bilirubin toxicity, frequently characterized by choreoathetoid cerebral palsy, upward gaze paralysis, and auditory neuropathy spectrum disorders with or without hearing loss.

We conducted an electronic search of National Guideline Clearinghouse (www.guideline.gov and www.g-i-n.net/), PubMed, Scopus, Ovid EMBASE, and the Cumulative Index to Nursing and
Allied Health Literature (CINAHL), as well as the references in relevant guidelines and review papers on ET for hyperbilirubinemia between January 1990 and June 2015. The search terms were: 'neonatal hyperbilirubinemia', 'neonatal jaundice', 'exchange transfusion', 'bilirubin encephalopathy', and/or 'kernicterus'. Guidelines without any specific criteria for ET or an English version were excluded from the final review. As this paper was designed as a narrative review, no systematic evaluation of the retrieved articles and reports was undertaken.

\section{Results}

\section{Current Criteria for ET in Developed Countries}

An overview of the recommended criteria for ET in published guidelines is presented in table $1[2,7,15-30]$. The AAP guidelines, first published in 1994 and updated in 2004 [7], have been adopted, with or without modifications, in many countries. Nomograms recommend intervention levels for phototherapy and ET based on the TSB level and postnatal age to reflect the perceived increased risk using gestational age and certain clinical factors. ET is warranted whenever intensive phototherapy does not significantly lower TSB levels at the exchange threshold for that age or whenever a baby shows signs of intermediate-to-advanced stages of ABE even if the TSB is falling. The AAP guideline considers TSB $\geq 25 \mathrm{mg} / \mathrm{dl}(428 \mu \mathrm{mol} / \mathrm{l})$ at any time to be a medical emergency requiring immediate intensive phototherapy preparatory to ET. Countries like Canada [15], The Netherlands [18], Australia [21], South Africa [24], and India [25-27] have adopted these criteria with little or no modifications (table 1). A few countries like Switzerland [19] and Norway [16] have incorporated baby weight in addition to or in lieu of gestational age into their guidelines. In Israel, separate ET thresholds are provided for infants with hemolytic and nonhemolytic conditions [23].

\section{Criteria for ET in Resource-Poor Countries}

Clinical guidelines for neonatal jaundice do not exist in the vast majority of LMIC. In the few countries (e.g. India and Kenya) where consensus guidelines have been established, the criteria for ET have been adapted from AAP and National Institute for Clinical Excellence (NICE; UK) guidelines (table 1). The clinical reference material, widely promoted by the World Health Organization for the care of sick infants in LMIC, recommends ET at TSB $\geq 15$ $\mathrm{mg} / \mathrm{dl}(260 \mu \mathrm{mol} / \mathrm{l})$ on the first day of life and TSB $\geq 25$ $\mathrm{mg} / \mathrm{dl}(425 \mu \mathrm{mol} / \mathrm{l})$ on the second day of life [30]. The threshold is lowered by at least $5 \mathrm{mg} / \mathrm{dl}$ for high-risk infants with evidence of hemolysis or sepsis. A major limita- 
Table 1. Overview of the criteria for ET in published guidelines for the management of neonatal hyperbilirubinemia

Country/ Reference Criteria for ET in near- and full-term infants
region

USA American Academy of Pediatrics [7]
Calibrated based on gestational age, postnatal age, and risk profile

In the first $24 \mathrm{~h}$ : TSB $12-19 \mathrm{mg} / \mathrm{dl}$

Between $1-3$ days: TSB $15-25 \mathrm{mg} / \mathrm{dl}$

At at least 4 days: TSB $\geq 25 \mathrm{mg} / \mathrm{dl}(428 \mu \mathrm{mol} / \mathrm{l})$ and does not decrease sufficiently with phototherapy alone

Immediate ET for any infant who is jaundiced and manifests the signs of the intermediate to advanced stages of acute bilirubin encephalopathy (hypertonia, arching, retrocollis, opisthotonos, fever, and a high-pitched cry) even if the TSB is falling

UK National Institute for Health and Clinical Excellence [2]

Different charts have been prepared for infants with a gestational age of 24-38 weeks or more

ET for babies whose serum bilirubin level indicates a need for it (as assessed by the threshold table and treatment threshold graphs) and/or babies with clinical features and signs of $\mathrm{ABE}$

Canada Canadian Paediatric Society [15]

ET should only be performed in centers with the appropriate expertise under the supervision of an experienced neonatologist

Treatment chart is adapted from AAP criteria and the TSB level is calibrated only in micromoles per liter

Infants with a TSB concentration above the thresholds shown in the chart should have immediate intensive phototherapy and should be referred for further investigation and preparation for ET; infants with clinical signs of acute bilirubin encephalopathy should have an immediate ET

Norway Bratlid et al. [16]

Denmark Ebbesen et al. [17]

The Dijk et al. [18]

Netherlands

Dijk et al. [18]

Birth weight is used as a measure of prematurity instead of gestational age as in the AAP guideline; the guidelines therefore include treatment recommendations for low, very low, and extremely low birth weight infants

ET is recommended for infants with nonhemolytic hyperbilirubinemia at a TSB level of $50-100 \mu \mathrm{mol} / \mathrm{l}$ above the maximum concentration for phototherapy, giving an indication for ET of $450 \mu \mathrm{mol} / \mathrm{l}$ in term infants with nonhemolytic

hyperbilirubinemia

ET for all infants when the TSB level is $100 \mu \mathrm{mol} / \mathrm{l}$ above the phototherapy limit (300 $\mu \mathrm{mol} / \mathrm{l} \pm 50 \mu \mathrm{mol} / \mathrm{l})$

ET when the TSB level rises by more than $10 \mu \mathrm{mol} / \mathrm{l} / \mathrm{h}$ during intensive phototherapy or if the TSB level does not fall considerably during double/triple phototherapy

Treatment chart adapted from AAP criteria

ET is planned when the TSB value is above the ET border or if despite intensive phototherapy the concentration of TSB does not fall and the ET limit is approaching Immediate ET if there are signs of acute bilirubin-encephalopathy or if the TSB level is above the ET border by more than $85 \mu \mathrm{mol} / \mathrm{l}$

Switzerland Swiss Society of Neonatology Treatment chart based on risk profile [19]

Term infant $>2,500 \mathrm{~g}$, healthy: $400-430 \mu \mathrm{mol} / \mathrm{l}$

Term infant $>2,500 \mathrm{~g}$, ill or with hemolysis: $350-370 \mu \mathrm{mol} / 1$

Premature infant of 35 and 36 weeks of gestation or term infant <2,500 g: 270-320 $\mu \mathrm{mol} / 1$

Italy Romagnoli et al. [20]
Separate treatment charts for hemolytic and nonhemolytic jaundice

TSB threshold for ET in newborns with nonhemolytic jaundice are generally 5-6 $\mathrm{mg} / \mathrm{dl}$ higher than the TSB threshold for phototherapy

The TSB threshold for ET in newborns with Rh or ABO hemolytic jaundice is lower than that of newborns with nonhemolytic jaundice

ET if the TSB level is $\geq 5 \mathrm{mg} / \mathrm{dl}(85 \mu \mathrm{mol} / \mathrm{l})$ above the ET threshold

ET if the TSB level exceeds the ET threshold after $4 \mathrm{~h}$ of intensive phototherapy

The TSB level continues to rise by more than $1 \mathrm{mg} / \mathrm{dl} / \mathrm{h}$ during intensive

phototherapy

Infants with clinical signs and symptoms of ABE are present 
Table 1 (continued)

\begin{tabular}{|c|c|c|}
\hline $\begin{array}{l}\text { Country/ } \\
\text { region }\end{array}$ & Reference & Criteria for ET in near- and full-term infants \\
\hline Australia & $\begin{array}{l}\text { Queensland Maternity and } \\
\text { Neonatal Clinical Guidelines } \\
\text { Program [21] }\end{array}$ & $\begin{array}{l}\text { Treatment chart adapted from AAP criteria } \\
\text { ET if the TSB level is above the ET threshold and is not expected to be below the } \\
\text { threshold after } 6 \text { h of continuous multiple phototherapy } \\
\text { Immediate ET in infants with signs of bilirubin encephalopathy }\end{array}$ \\
\hline New Zealand & $\begin{array}{l}\text { Auckland District Health } \\
\text { Board [22] }\end{array}$ & $\begin{array}{l}\text { Treatment chart for infants without hemolytic jaundice } \\
\text { ET in infants with a TSB level }>510 \mu \mathrm{mol} / \mathrm{l} \text { from the second day of life } \\
\text { Consider ET in infants with a TSB level }>50 \mu \mathrm{mol} / \mathrm{l} \text { above the threshold for } \\
\text { phototherapy }\end{array}$ \\
\hline Israel & Kaplan et al. [23] & $\begin{array}{l}\text { Adapted from an AAP nomogram and presented in a tabular format } \\
\text { Separate tables for hemolytic and nonhemolytic jaundice, e.g. } \\
\text { ET in term infants with hemolytic jaundice initiated at TSB levels of } 18-20 \mathrm{mg} / \mathrm{dl} \\
\text { from } 24 \mathrm{~h} \text { after birth } \\
\text { ET in term infants with nonhemolytic jaundice initiated at TSB } 20-25 \mathrm{mg} / \mathrm{dl} \text { from } \\
24 \mathrm{~h} \text { after birth } \\
\text { In less acute situations, ET is recommended after a trial of } 3-4 \mathrm{~h} \text { of intensive } \\
\text { phototherapy }\end{array}$ \\
\hline South Africa & Horn et al. [24] & AAP nomogram for ET adopted without any modifications \\
\hline India & $\begin{array}{l}\text { National Neonatal Forum of } \\
\text { India [25] }\end{array}$ & $\begin{array}{l}\text { AAP criteria for ET is recommended } \\
\text { Immediate EBT is recommended if the infant shows signs of ABE or if the TSB level } \\
\text { is } \geq 5 \mathrm{mg} / \mathrm{dl} \text { above the recommended values }\end{array}$ \\
\hline & Mishra et al. [26] & $\begin{array}{l}\text { AAP criteria for ET is recommended } \\
\text { Additional criteria for hemolytic jaundice is recommended } \\
\text { Initiate ET if the TSB level: } \\
\text { is } \geq 10 \mathrm{mg} / \mathrm{dl} \text { up to } 24 \mathrm{~h} \text { of life } \\
\text { is } \geq 15 \mathrm{mg} / \mathrm{dl} \text { at } 25-48 \mathrm{~h} \text { of life } \\
\text { is } \geq 20 \mathrm{mg} / \mathrm{dl} \text { at } 48 \mathrm{~h} \text { of life or later } \\
\text { rises at a rate } \geq 0.5 \mathrm{mg} / \mathrm{dl} / \mathrm{h}\end{array}$ \\
\hline & $\begin{array}{l}\text { Postgraduate Institute of } \\
\text { Medical Education and } \\
\text { Research [27] }\end{array}$ & $\begin{array}{l}\text { Consider ET if the TSB level rises at a rate }>1 \mathrm{mg} / \mathrm{dl} / \mathrm{h} \text { despite } \mathrm{PT} \text { or rises at a rate } \\
>0.5 \mathrm{mg} / \mathrm{dl} / \mathrm{h} \text { despite PT if the hemoglobin level is between } 10-12 \mathrm{~g} / \mathrm{dl} \\
\text { Any TSB level }>12 \mathrm{mg} / \mathrm{dl} \text { in first } 12 \mathrm{~h} \text { and any TSB level }>20 \mathrm{mg} / \mathrm{dl} \text { in the neonatal } \\
\text { period in the setting of hemolysis } \\
\text { In the DVET zone as per AAP charts for near-term and term } \\
\text { babies }\end{array}$ \\
\hline Kenya & $\begin{array}{l}\text { Ministry of Health of the } \\
\text { Republic of Kenya [28] }\end{array}$ & $\begin{array}{l}\text { Adapted from NICE criteria and presented in a tabular format } \\
\text { Initiate ET unless the TSB falls below the following thresholds while treatment is } \\
\text { being prepared: } \\
>100 \mu \mathrm{mol} / \mathrm{l} \text { within } 24 \mathrm{~h} \text { of life } \\
>300 \mu \mathrm{mol} / \mathrm{l} \text { at } 24-36 \mathrm{~h} \text { of life } \\
>450 \mu \mathrm{mol} / \mathrm{l} \text { after } 42 \mathrm{~h} \text { of life }\end{array}$ \\
\hline Malaysia & $\begin{array}{l}\text { Ministry of Health of } \\
\text { Malaysia [29] }\end{array}$ & $\begin{array}{l}\text { Adapted from AAP and College of Family Physicians of Canada criteria } \\
\text { ET is recommended if TSB levels, though declining with intensive phototherapy, } \\
\text { persists above the ET thresholds }(>400 \mu \mathrm{mol} / \mathrm{l} \text { after } 24 \mathrm{~h}) \\
\text { ET is recommended in infants whose levels continue to rise to ET levels despite } \\
\text { being on phototherapy } \\
\text { ET is initiated in healthy term infants when the TSB level is }>340 \mu \mathrm{mol} / \mathrm{l} \text { from } 24 \mathrm{~h} \\
\text { of life }\end{array}$ \\
\hline $\begin{array}{l}\text { All developing } \\
\text { countries }\end{array}$ & $\begin{array}{l}\text { World Health Organization } \\
\text { [30] }\end{array}$ & $\begin{array}{l}\text { ET is recommended at the following thresholds: } \\
\text { day } 1: \mathrm{TSB} \geq 260 \mu \mathrm{mol} / \mathrm{l}(15 \mathrm{mg} / \mathrm{dl}) \text { for infants } \geq 35 \text { weeks } \\
\text { day } 2 / 3: \mathrm{TSB} \geq 425 \mu \mathrm{mol} / \mathrm{l}(25 \mathrm{mg} / \mathrm{dl}) \text { for infants } \geq 35 \text { weeks }\end{array}$ \\
\hline
\end{tabular}


tion of this protocol is the daily rather than 6- to 12-hourly monitoring of jaundiced infants especially when ET may be required for rapidly rising TSB in the first $48 \mathrm{~h}$ of life.

Reported practices also vary between and within countries $[5,11,31,32]$. For example, in one hospital in Iraq, indications for ET included all infants admitted with TSB $>20 \mathrm{mg} / \mathrm{dl}(342 \mu \mathrm{mol} / \mathrm{l})$ and/or clinical signs of bilirubininduced neurologic dysfunction (BIND), except when the infant clearly responded to intensive phototherapy prior to availability of blood for ET [11]. In another hospital in Egypt, ET was indicated when phototherapy failed to reduce the TSB level to $<25 \mathrm{mg} / \mathrm{dl}(428 \mu \mathrm{mol} / \mathrm{l})$ in healthy term infants or to lower thresholds in the presence of neurotoxicity risk factors, including prematurity, severe hemolysis, significant lethargy, and temperature instability [31]. In Nigeria, ET is routinely indicated at TSB $\geq 20 \mathrm{mg} /$ $\mathrm{dl}(340 \mu \mathrm{mol} / \mathrm{l})$ in apparently healthy term infants and sometimes at TSB $<20 \mathrm{mg} / \mathrm{dl}(340 \mu \mathrm{mol} / \mathrm{l})$ in very ill term infants with or without features of kernicterus, and at TSB levels between 10 and $12 \mathrm{mg} / \mathrm{dl} / \mathrm{kg}(170-204 \mu \mathrm{mol} / \mathrm{l})$ in preterm infants [32]. In India, some hospitals simply use the medium- and high-risk thresholds for intervention in AAP nomograms for all infants [5].

\section{Discussion}

The overarching finding from this review is that the decision to initiate ET to prevent or minimize the risk of kernicterus crucially depends on 3 main considerations: (1) accurate TSB measurement, (2) accurate evaluation of clinical risk factors, and (3) accurate clinical assessment of the neurological state. The available evidence of the effectiveness of ET itself is largely based on a consensus among experts rather than classic evidence from randomized controlled trials $[2,3]$. This is possibly because it is ethically not permissible to prospectively assign infants with $\mathrm{SNH}$ randomly to either phototherapy or the more risky ET regardless of their risk status. The only randomized controlled trial so far reporting the effectiveness of ET in preventing bilirubin-induced mortality (albeit compared to simple transfusion for the relief of anemia) was conducted in 1952, before the advent of phototherapy $[33,34]$.

Real-time and/or point-of-care TSB remains the gold standard for estimating and monitoring the severity of jaundice. However, neonatal units in many LMIC lack side laboratory to support real-time TSB measurement. Rather, blood samples have to be conveyed to a central laboratory where the results may take $2-4 \mathrm{~h}$ before be- coming available for decision-making. The noninvasive transcutaneous bilirubin measurement is therefore more widely used. Though it is valuable as a screening tool, it is inaccurate for measuring high TSB levels likely to produce $A B E$ and may not be affordable in many resourcelimited settings $[35,36]$. Transcutaneous bilirubin values above $12 \mathrm{mg} / \mathrm{dl}(205 \mu \mathrm{mol} / \mathrm{l})$ also need to be confirmed via TSB measurement before initiating ET [36]. A lowcost, minimally invasive point-of-care instrument for measuring the total plasma bilirubin concentration is currently being piloted and holds promise for LMIC [37].

Although the precise mechanisms of bilirubin-induced cytotoxicity have not been fully understood, clinical assessment of the risk of neurotoxicity is most commonly guided by prespecified TSB thresholds based on gestational and postnatal age. The limitation of sole reliance on TSB as a predictor of neurotoxicity or as the primary intervention/outcome measure has been highlighted in several reports $[3,38]$. In particular, TSB has been shown to have a high sensitivity but a low specificity for identifying infants at risk of ABE. Since only unbound free bilirubin can cross the blood-brain barrier, the level of plasma-free bilirubin is considered to be a more reliable index of the risk of neurotoxicity and acute auditory impairment than TSB [39]. However, presently, it cannot be measured routinely in most clinical settings. Use of the bilirubin/albumin ratio as a surrogate for plasma-free bilirubin had been suggested because it contains 2 of the 3 components for deriving free bilirubin (i.e. TSB, albumin, and the binding constant K) [38-40]. Despite this, clinical studies, especially in preterm infants, have demonstrated that bilirubin/albumin does not improve the prediction of ABE or residual encephalopathy over TSB alone [40]. The same findings have also been demonstrated in nearterm and full-term infants in LMIC [41].

Clinical risk factors promoting neurotoxicity at lower TSB levels include prematurity, hemolytic disease, G6PD deficiency, asphyxia, sepsis, acidosis, and hypoalbuminemia $(<3 \mathrm{~g} / \mathrm{dl})[7,42]$. It is difficult to accurately determine most of these factors routinely in LMIC. Gestational age, most frequently used for risk factor determination, may be difficult to ascertain where women do not attend regular antenatal care and deliver at home. Birth weight or weight at admission ( $\geq 2.0 \mathrm{~kg}$ ) is a commonly used threshold for late-preterm and term infants. Sepsis is often based on clinical assessment rather than on laboratory confirmation, and it is more frequently overdiagnosed. While routine testing for blood group incompatibilities is widespread, passive immunization for rhesus disease is either not available or prohibitively expensive 
in most LMIC. Although cost-effective tools for routine G6PD screening are presently available, universal screening is lacking even in LMIC with a significant G6PD deficiency [43]. Simple and inexpensive technologies for detecting morphological abnormalities of erythrocytes leading to hemolytic jaundice have also been reported and can be utilized in resource-poor settings [44]. These issues need to be addressed systematically to enhance the decision-making process for ET.

In LMIC, a high proportion of babies with $\mathrm{SNH}$ are born outside hospital settings, while the onset of jaundice more frequently occurs at home. It is common for mothers and caregivers to first attempt home treatment, failing which medical intervention is sought, usually when the child is irritable, is unable to feed, or becomes lethargic [45]. Many infants therefore present late with early signs of $\mathrm{ABE}$ or symptoms of intermediate/advanced $\mathrm{ABE}$. The BIND scoring system is a useful clinical tool for identifying infants with $\mathrm{ABE}[46,47]$. A modified version of the protocol (BIND-M) has been validated for use in resource-poor countries [47]. It incorporates an additional component for abnormal eye movements to improve its clinical effectiveness in the identification of the various degrees of $\mathrm{ABE}$, especially by primary care physicians. For in-born babies, predischarge TSB screening along with assessment of clinical risk factors to identify infants at risk of SNH should be routinely considered [7, 42].

These 3 criteria may present in a variety of combinations and exert a considerable influence on judgement when assessing the risk of kernicterus. Decision-making will be compounded by the fact that there is presently no consistency in TSB thresholds for ET among infants with or without evidence of neurotoxicity, stratified by neurological status, for assessing the risk of kernicterus. For example, some reports suggest that TSB levels between 25 $\mathrm{mg} / \mathrm{dl}(428 \mu \mathrm{mol} / \mathrm{l})$ and $30 \mathrm{mg} / \mathrm{dl}(513 \mu \mathrm{mol} / \mathrm{l})$ in infants without neurotoxicity risk factors are rarely associated with intermediate/advanced $\mathrm{ABE}[3,31,41,48]$. Other authors have argued that ET should be considered only when the TSB level is $15 \mathrm{mg} / \mathrm{dl}(257 \mu \mathrm{mol} / \mathrm{l})$ or more above the AAP threshold, which translates to TSB $>35$ $\mathrm{mg} / \mathrm{dl}(600 \mu \mathrm{mol} / \mathrm{l})[49,50]$. In contrast, a threshold of TSB $>20 \mathrm{mg} / \mathrm{dl}(342 \mu \mathrm{mol} / \mathrm{l})$ is advocated for ET in infants with neurotoxicity risk factors, especially in countries with a high prevalence of G6PD deficiency $[32,51]$. A practical approach that reflects these criteria and possibilities in a way that can facilitate decision-making by clinicians is therefore essential and worth exploring. Where ET facilities are limited, it may be necessary, in particular, to prioritize infants based on such individual risk assess- ments. The decision to initiate ET must also take into consideration the timing of ET vis-à-vis the complex interaction between the magnitude and duration of exposure of the neuronal cells to unbound bilirubin [52].

The procedural steps and delays often encountered between the time the decision to initiate is made and the ET is conducted are outside the scope of this review. However, the roughly 6- to 24-hour delay in conducting the ET often offers an opportunity to establish whether the TSB level can be lowered with phototherapy. Intensive phototherapy (with irradiance maintained at levels $\geq 30 \mu \mathrm{W} /$ $\mathrm{cm}^{2} / \mathrm{nm}$ ) is critical to reducing the need for ET in all infants with $\mathrm{SNH}$, with or without $\mathrm{ABE}$ and neurotoxicity risk factors, and to halting the potential damage that may occur while waiting for the exchange $[7,53]$. However, in many LMIC the availability of effective phototherapy is frequently constrained by erratic power supply, inadequate skin exposure due to overcrowding (with multiple infants placed under a single device), suboptimal irradiance levels, and poor device maintenance. Practical steps for addressing these and related issues have been discussed in greater detail elsewhere [35]. The use of filtered sunlight phototherapy as a possible alternative in tropical regions is also currently being piloted in Nigeria [54].

\section{Conclusions}

ET is an effective treatment for preventing or limiting BIND in infants with $\mathrm{SNH}$; however, it is not entirely risk free and needs to be initiated after careful evaluation of the risk of kernicterus. A tool that incorporates TSB thresholds, the presence or absence of neurotoxicity risk factors with clinical signs of $\mathrm{ABE}$ in the jaundiced infant should facilitate more accurate decision making. In settings where the requirement for ET is high but available resources are limited, this tool can also be used to prioritize infants based on the risk assessment for kernicterus. Provision of effective phototherapy along with interventions addressing the socio-cultural, biological, genetic, and systems-based factors that lead to excessive rates of ET in LMIC should also be addressed.

\section{Acknowledgements}

The authors received valuable comments from Michael Kaplan, Thomas Newman, Tinuade Ogunlesi, and Richard Wennberg on an earlier draft of this paper. 


\section{References}

1 Diamond LK: Replacement transfusion as a treatment for erythroblastosis fetalis. Pediatrics 1948;2:520-524.

2 National Institute for Health and Clinical Excellence: Neonatal jaundice: clinical guideline 98. 2010. http://www.nice.org.uk/CG98 (accessed July 14, 2015).

3 Ip S, Chung M, Kulig J, O’Brien R, Sege R, Glicken S, Maisels MJ, Lau J; American Academy of Pediatrics Subcommittee on Hyperbilirubinemia: An evidence-based review of important issues concerning neonatal hyperbilirubinemia. Pediatrics 2004;114:e130e153.

4 Salas AA, Mazzi E: Exchange transfusion in infants with extreme hyperbilirubinemia: an experience from a developing country. Acta Paediatr 2008;97:754-758.

5 Murki S, Kumar P: Blood exchange transfusion for infants with severe neonatal hyperbilirubinemia. Semin Perinatol 2011;35:175184.

6 Jackson JC: Adverse events associated with exchange transfusion in healthy and ill newborns. Pediatrics 1997;99:E7.

7 American Academy of Pediatrics: Management of hyperbilirubinaemia in the newborn infant 35 or more weeks of gestation. Pediatrics 2004;114:297-316.

8 Steiner LA, Bizzarro MJ, Ehrenkranz RA, Gallagher PG: A decline in the frequency of neonatal exchange transfusions and its effect on exchange-related morbidity and mortality. Pediatrics 2007;120:27-32.

9 Chitty HE, Ziegler N, Savoia H, Doyle LW, Fox LM: Neonatal exchange transfusions in the 21 st century: a single hospital study. J Paediatr Child Health 2013;49:825-832.

10 Owa JA, Ogunlesi TA: Why we are still doing so many exchange blood transfusion for neonatal jaundice in Nigeria. World J Pediatr 2009;5:51-55

11 Hameed NN, Na' Ma AM, Vilms R, Bhutani VK: Severe neonatal hyperbilirubinaemia and adverse short-term consequences in Baghdad, Iraq. Neonatology 2011;100:57-63.

12 Rasul CH, Hasan MA, Yasmin F: Outcome of neonatal hyperbilirubinemia in a tertiary care hospital in Bangladesh. Malays J Med Sci 2010;17:40-44.

13 Iskander I, Gamaleldin R, Kabbani M: Root causes for late presentation of severe neonatal hyperbilirubinaemia in Egypt. East Mediterr Health J 2012;18:882-887.

14 Murray NA, Roberts IA: Neonatal transfusion practice. Arch Dis Child Fetal Neonatal Ed 2004;89:F101-F107.

15 Canadian Paediatric Society: Guidelines for detection, management and prevention of hyperbilirubinemia in term and late preterm newborn infants (35 or more weeks' gestation). Paediatr Child Health 2007;12:1B-12B.
16 Bratlid D, Nakstad B, Hansen TW: National guidelines for treatment of jaundice in the newborn. Acta Paediatr 2011;100:499-505.

17 Ebbesen F, Bjerre JV, Vandborg PK: Relation between serum bilirubin levels $\geq 450 \mu \mathrm{mol} / \mathrm{l}$ and bilirubin encephalopathy; a Danish population-based study. Acta Paediatr 2012;101: 384-389.

18 Dijk PH, de Vries TW, de Beer JJ; Dutch Pediatric Association: Guideline 'Prevention, diagnosis and treatment of hyperbilirubinemia in the neonate with a gestational age of 35 or more weeks' (in Dutch). Ned Tijdschr Geneeskd 2009;153:A93.

19 Swiss Society of Neonatology: Assessment and treatment of jaundiced newborn infants $350 / 7$ or more weeks of gestation. http:// www.neonet.ch/assets/pdf/2006_BiliEmpfehlungen_e_final.pdf.

20 Romagnoli C, Barone G, Pratesi S, Raimondi F, Capasso L, Zecca E, Dani C; Task Force for Hyperbilirubinaemia of the Italian Society of Neonatology: Italian guidelines for management and treatment of hyperbilirubinaemia of newborn infants $\geq 35$ weeks' gestational age. Ital J Pediatr 2014;40:11.

21 Queensland Maternity and Neonatal Clinical Guidelines Program: Queensland Maternity and Neonatal Clinical Guideline: Neonatal Jaundice. 2012. http://www.health.qld.gov. $\mathrm{au} / \mathrm{qcg} /$ documents/g_jaundice.pdf.

22 Auckland District Health Board: Newborn Services Clinical Guideline: Management of Neonatal Jaundice. 2012. http://www.adhb. govt.nz/newborn/Guidelines/GI/Jaundice. htm.

23 Kaplan M, Merlob P, Regev R: Israel guidelines for the management of neonatal hyperbilirubinemia and prevention of kernicterus. J Perinatol 2008;28:389-397.

24 Horn AR, Kirsten GF, Kroon SM, Henning PA, Möller G, Pieper C, et al: Phototherapy and exchange transfusion for neonatal hyperbilirubinaemia: neonatal academic hospitals' consensus guidelines for South African hospitals and primary care facilities. S Afr Med J 2006;96:819-24.

25 National Neonatal Forum of India: Management of neonatal hyperbilirubinemia. http:// www.nnfpublication.org.

26 Mishra S, Agarwal R, Deorari AK, Paul VK Jaundice in the newborns. Indian J Pediatr 2008;75:157-163.

27 Postgraduate Institute of Medical Education and Research: Jaundice; in Dutta S, Kumar P (eds): The PGI NICU Handbook of Protocols, ed 4. Chandigarh, The New Heart Trust, 2010.

28 Ministry of Health of the Republic of Kenya: Basic Paediatric Protocols for Ages up to 5 Years. Nairobi, Ministry of Health of the Republic of Kenya, 2013, pp 40-42.

29 Ministry of Health of Malaysia: Management of jaundice in healthy term newborns: Clinical practice guidelines. 2003. http://www. acadmed.org.my/index.cfm? \&menuid=67.
30 World Health Organization: Pocket Book of Hospital Care for Children, ed 2: Guidelines for the Management of Common Childhood Illnesses. Geneva, WHO, 2013.

31 Gamaleldin R, Iskander I, Seoud I, Aboraya $\mathrm{H}$, Aravkin A, Sampson PD, Wennberg RP: Risk factors for neurotoxicity in newborns with severe neonatal hyperbilirubinemia. Pediatrics 2011;128:e925-e931.

32 Olusanya BO, Osibanjo FB, Mabogunje CA, Slusher TM, Olowe SA: The burden and management of neonatal jaundice in Nigeria: a scoping review of the literature. Niger J Clin Pract, in press.

33 Mollison PL, Walker W: Controlled trials of the treatment of haemolytic disease of the newborn. Lancet 1952;1:429-433.

34 Dijk PH, Hulzebos CV: An evidence-based view on hyperbilirubinaemia. Acta Paediatr Suppl 2012;101:3-10.

35 Olusanya BO, Ogunlesi TA, Kumar P, Boo NY, Iskander IF, de Almeida MF, Vaucher YE, Slusher TM: Management of late-preterm and term infants with hyperbilirubinaemia in resource-constrained settings. BMC Pediatr 2015;15:39.

36 De Luca D, Jackson GL, Tridente A, Carnielli VP, Engle WD: Transcutaneous bilirubin nomograms: a systematic review of population differences and analysis of bilirubin kinetics. Arch Pediatr Adolesc Med 2009;163:10541059.

37 Coda Zabetta CD, Iskander IF, Greco C, Bellarosa C, Demarini S, Tiribelli C, Wennberg RP: Bilistick: a low-cost point-of-care system to measure total plasma bilirubin. Neonatology 2013;103:177-181.

38 Watchko JF: Recent advances in the management of neonatal jaundice. Res Rep Neonatol 2014;4:183-193.

39 Ahlfors CE: Predicting bilirubin neurotoxicity in jaundiced newborns. Curr Opin Pediatr 2010;22:129-133.

40 Hulzebos CV, Dijk PH: Bilirubin-albumin binding, bilirubin/albumin ratios, and free bilirubin levels: where do we stand? Semin Perinatol 2014;38:412-421.

41 Iskander I, Gamaleldin R, El Houchi S, El Shenawy A, Seoud I, El Gharbawi N, AbouYoussef H, Aravkin A, Wennberg RP: Serum bilirubin and bilirubin/albumin ratio as predictors of bilirubin encephalopathy. Pediatrics 2014;134:e1330-e1339.

42 Maisels MJ, Bhutani VK, Bogen D, Newman TB, Stark AR, Watchko JF: Hyperbilirubinemia in the newborn infant $>$ or $=35$ weeks' gestation: an update with clarifications. Pediatrics 2009;124:1193-1198.

43 Olusanya BO, Emokpae AA, Zamora TG, Slusher TM: Addressing the burden of neonatal hyperbilirubinaemia in countries with significant glucose-6-phosphate dehydrogenase deficiency. Acta Paediatr 2014;103:11021109. 
44 Christensen RD, Yaish HM, Lemons RS: Neonatal hemolytic jaundice: morphologic features of erythrocytes that will help you diagnose the underlying condition. Neonatology 2014;105:243-249.

45 Olusanya BO, Ogunlesi TA, Slusher TM: Why is kernicterus still a major cause of death and disability in low-income and middle-income countries? Arch Dis Child 2014;99:11171121.

46 Johnson L, Brown AK, Bhutani VK: BIND - a clinical score for bilirubin induced dysfunction in newborns. Pediatrics 1999;104:746747.

47 Radmacher PG, Groves FD, Owa JA, Ofovwe GE, Amuabunos EA, Olusanya BO, Slusher TM: Evaluating the severity of neonatal jaundice using a Modified bind score in a resource-constrained setting. BMC Pediatr 2015;15:28.
48 Newman TB, Liljestrand P, Jeremy RJ, Ferriero DM, Wu YW, Hudes ES, Escobar GJ; Jaundice and Infant Feeding Study Team: Outcomes among newborns with total serum bilirubin levels of $25 \mathrm{mg}$ per deciliter or more. N Engl J Med 2006;354:1889-1900.

49 Sgro M, Campbell D, Barozzino T, Shah V: Acute neurological findings in a national cohort of neonates with severe neonatal hyperbilirubinemia. J Perinatol 2011;31:392-396.

50 Kuzniewicz MW, Wickremasinghe AC, Wu YW, McCulloch CE, Walsh EM, Wi S, Newman TB: Incidence, etiology, and outcomes of hazardous hyperbilirubinemia in newborns. Pediatrics 2014;134:504-509.
51 Kaplan M, Bromiker R, Hammerman C: Severe neonatal hyperbilirubinemia and kernicterus: are these still problems in the third millennium? Neonatology 2011;100:354-362.

52 Bhutani VK, Johnson L: The jaundiced newborn in the emergency department: prevention of kernicterus. Clin Ped Emerg Med 2008;9:149-159.

53 Edris AA, Ghany EA, Razek AR, Zahran AM: The role of intensive phototherapy in decreasing the need for exchange transfusion in neonatal jaundice. J Pak Med Assoc 2014;64:5-8.

54 Slusher TM, Olusanya BO, Vreman HJ, Brearly AM, Vaucher YE, Lund TC, Wong RJ, Emokpae AA, Stevenson DK: A randomized trial of filtered sunlight phototherapy in African neonates. New Engl J Med 2015;373: 1115-1124. 